\title{
Efeitos das transferências fiscais sobre as despesas dos estados brasileiros
}

\author{
Bárbara Françoise Cardoso ${ }^{1}$ \\ Jean dos Santos Nascimento ${ }^{2}$ \\ Adriano Nascimento da Paixão ${ }^{3}$
}

\begin{abstract}
Resumo: Os estados brasileiros recebem transferências fiscais da União para que possam complementar as verbas disponíveis para o cumprimento dos seus orçamentos e garantir sua autonomia política e fiscal. Contudo, corre-se o risco de eles gastarem excessivamente quanto mais transferências fiscais eles recebem, principalmente as do tipo desvinculadas. Diante esse possível distúrbio das transferências sobre os gastos, procurou-se responder à seguinte questão: as transferências fiscais vinculadas e desvinculadas apresentam efeitos expansivos sobre as despesas públicas dos estados brasileiros? Para respondê-la, o trabalho teve como objetivo verificar se essas transferências expandem os gastos dos estados brasileiros de forma desproporcional ao aumento da renda. Para isso foi utilizado um modelo econométrico de dados em painel junto a variáveis fiscais, econômicas e demográficas, no período compreendido entre 2000 e 2008. As transferências vinculadas e desvinculadas não tiveram efeito expansivo, apresentando impacto sobre os gastos menor que o da renda e o das receitas tributárias.
\end{abstract}

Palavras-chaves: Transferências fiscais; despesas públicas; dados em painel.

JEL: H2; H2O.

1 Doutoranda em Desenvolvimento Regional e Agronegócio pela Universidade Estadual do Oeste do Paraná (Unoeste). E-mail: barbarafcardoso@gmail.com

2 Doutor em Economia Aplicada pela Universidade Federal de Viçosa (UFV). Professor do Colegiado de Economia e do Programa de Pós-Graduação em Desenvolvimento Regional da Universidade Federal de Tocantins (UFT). E-mail: jean.sn@gmail.com

3 Doutor e Economia Aplicada pela Universidade Federal de Viçosa (UFV). Professor do Departamento de Economia da Universidade Federal da Paraíba (UFPB) e do Programa de Pós-Graduação em Desenvolvimento Regional da Universidade Federal do Tocantins (UFT). E-mail: anpaixao@gmail.com 


\title{
Effects of tax changes on the costs of brazilian states
}

\begin{abstract}
The Brazilian states receive fiscal transfers from the Union so they can supplement the funds available to meet their budgets and ensure its political and fiscal autonomy. However, it runs the risk that they spend too much more fiscal transfers they receive, especially the kind of detached. Faced with this potential disorder on the transfer spending, we tried to answer the following question: fiscal transfers linked and unlinked have expansive effects on public expenditure of the Brazilian states? To answer it, the study aimed to determine whether such transfers expand spending by Brazilian states disproportionately to the increase in income. For this we used an econometric model for panel data from the fiscal variables, economic and demographic in the period between 2000 and 2008. The transfers were not linked and unlinked expansive effect, with impact on spending less than the income and tax revenues.
\end{abstract}

Key-words: Fiscal transfers; public expenditure; panel data.

JEL: H2; H2O.

\section{Introdução}

No Brasil, o sistema federativo permite a autonomia dos seus estados e municípios, permitindo que cada um faça a arrecadação de alguns tributos para o cumprimento de seus próprios orçamentos. Contudo, o que é arrecadado nos estados e municípios não é o suficiente para arcar com todos os seus gastos, necessários para o atendimento das demandas locais. Por isso, há a necessidade de haver transferências fiscais intergovernamentais e de forma diferenciada.

Algumas dessas transferências derivam de arrecadações federais e a maior parcela se origina em estados pertencentes às regiões mais desenvolvidas, como o Sudeste e o Sul, e são distribuídas para todos os estados de modo que os pertencentes às regiões consideradas menos desenvolvidas (Norte, Nordeste e Centro-Oeste) recebam, em tese, proporcionalmente mais do que os estados das regiões Sudeste e Sul.

Nesta situação, as transferências fiscais tornam-se importantes instrumentos de descentralização dos tributos e de equilíbrio vertical, uma vez que concentra sua fonte de renda nas regiões mais desenvolvidas e sua distribuição nas menos desenvolvidas.

Quando os estados e municípios recebem mais transferências seus gastos podem expandir de forma mais que proporcional ao aumento do PIB e dos tributos. Se os gastos aumentarem proporcionalmente mais com o aumento 
das transferências fiscais do que com o aumento da renda, tem-se o chamado efeito flypaper que não é a situação ideal para o setor público. Este setor tende a gastar excessivamente quanto mais transferências fiscais recebe. O resultado final deste processo pode ser um desequilíbrio fiscal sério, o que viabilizaria a autonomia política dos estados e seu poder de atendimento das demandas locais. Diante esse possível distúrbio das transferências sobre os gastos, procura-se responder à seguinte questão: as transferências fiscais vinculadas e desvinculadas apresentam efeitos expansivos sobre as despesas públicas dos estados brasileiros? Parte-se da hipótese de há um efeito expansivo provocado pelas transferências.

Para responder a esta questão, o trabalho tem como objetivo verificar se as transferências vinculadas e desvinculadas expandem os gastos dos estados brasileiros de forma mais acentuada do que a renda e as receitas tributárias.

Este trabalho está dividido em cinco seções além desta introdução. A segunda seção explicita sobre algumas teorias que explicam, em parte, os determinantes das despesas públicas e sobre alguns aspectos básicos relacionados às principais transferências estaduais. Na seção 3 está exposto o método utilizado, detalhando-se o modelo, os dados e fontes de informações. A quarta seção apresenta algumas características das variáveis utilizadas e expõe os resultados do trabalho. A Seção 5 destaca as conclusões deste trabalho, enquanto a 6 apresenta as referências bibliográficas utilizadas.

\section{Teorias Explicativas das Despesas Públicas}

Existem algumas teorias que explicam, em parte, o comportamento das despesas públicas, como a Lei de Wagner, o Modelo de Peacock e Wiseman e a Teoria de Ilusão Fiscal.

A Lei de Wagner, segundo Mourão (2004), considera as despesas públicas como variável endógena explicada pelo PIB. Essa Lei afirma que as despesas crescem exponencialmente mais rápido que o produto da economia em um estado progressista e em escala maior em governos descentralizados. Por este motivo, esta Lei também é denominada Lei dos Dispêndios Públicos Crescentes. Assim, supõe-se que a elasticidade da renda seja positiva e maior que a unidade.

Corroborando com esta Lei, o Modelo de Peacock e Wiseman afirma que o aumento das despesas públicas é mais intenso após momentos excepcionais, como guerras, desastres naturais ou convulsões sociais. De acordo com Mourão (2004), este modelo mostra que há um efeito deslocamento nas despesas públicas. Wilges (2006) afirma que o efeito deslocamento é observado na receita tributária, que aumenta consideravelmente após algum momento 
excepcional. Contudo, para Peacock e Wiseman, o crescimento das despesas fica limitado ao das receitas tributárias devido à tolerância dos contribuintes.

Por outro lado, essa abordagem também relaciona mais dois efeitos ao efeito de deslocamento: os efeitos de inspeção e de concentração. Mourão (2004) explica que o efeito de inspeção é verificado após momentos excepcionais e afeta a estrutura orçamentária; e o efeito de concentração é verificado na tendência de centralização das decisões em momentos excepcionais.

A ilusão fiscal é outro fator explicativo das despesas públicas. Oates (1979) relata que este fato refere-se à ilusão que os eleitores têm de não pagar muitos tributos ou de não saberem seu volume, uma vez que a maioria destes encontra-se na forma indireta, ou seja, incluídos nos preços dos produtos. Logo, os governantes podem aumentar os impostos sem que os seus eleitores percebam e, assim, aumentar também as despesas públicas.

Em termos de transferências fiscais, quando governos recebem esses recursos pode não haver uma pressão tão excessiva por tributos locais. Desta forma, os contribuintes se sentem desobrigados pelas receitas extras (não tributárias) no orçamento fiscal e não acham tão necessário fiscalizar os níveis de despesas públicas. Como consequência, os governos expandem os gastos sem restrições excessivas por parte dos contribuintes, sendo, desta forma, as transferências fiscais um importante elemento que desfaz o elo entre receitas tributárias e despesas públicas. Em resultados econométricos, poder-se-ia esperar que os coeficientes das transferências fossem maiores que os da receita tributária, indicando o fenômeno da ilusão fiscal (Nascimento, 2010).

Poder-se-ia esperar ainda que o efeito das transferências fiscais sobre os gastos fosse positivo. Segundo Fisher (1981) e Ingberman e Inman (1987), se o coeficiente das transferências desvinculadas ${ }^{1}$ for maior que o do PIB (ou renda), está-se diante do efeito flypaper, que alude para o efeito expansivo das transferências sobre os gastos públicos ${ }^{2}$. Este efeito é muito comum nos estudos empíricos sobre transferências, sejam estaduais sejam municipais, e quer dizer que o dinheiro recebido pelo setor público tende a permanecer no orçamento do governo e o recebido pelo setor privado tende a permanecer neste ${ }^{3}$.

Uma das explicações para o efeito flypaper, segundo Varela, Martins e Fávero (2010), é que a população desconhece os efeitos das transferências sobre o setor público e isso favorece os gastos excessivos, e é exatamente esse um dos sentidos da "ilusão fiscal” discutido anteriormente. Portanto, na presença de ilusão fiscal, as transferências tenderiam a expandir os gastos dos governos de forma mais que proporcional ao aumento da renda.

1 A classificação das transferências fiscais para o propósito deste trabalho é mostrada na Seção 3.

2 Vários trabalhos encontraram este efeito; a este respeito ver Fisher (1981) e Hines e Thaler (1995).

3 Flypaper significa papel de pegar moscas. No contexto deste trabalho, quer-se aludir que o dinheiro gruda onde bate. De outra forma, se entra nos cofres públicos, permanece neles e expandem as despesas públicas, sendo que o mesmo ocorre no setor privado. 


\subsection{Aspectos básicos sobre as principais transferências estaduais ${ }^{4}$}

A principal transferência financeira recebida pelos Estados brasileiros é o Fundo de Participação dos Estados (FPE), que é considerado um instrumento de redistribuição de renda uma vez que, em tese, transfere parte da arrecadação tributária das regiões mais desenvolvidas para as menos desenvolvidas. De acordo com a Constituição Federal de 1988 (CF/88), o FPE é composto por 21,5\% da arrecadação advinda do Imposto sobre a Renda (IR) e do Imposto Sobre Produtos Industrializados (IPI) ${ }^{5}$.

A repartição de parcela da arrecadação do IPI entra na uma partilha fiscal de outra forma; o IPI-EXP é composto por 10\% da arrecadação do IPI e repassado às localidades exportadoras. Do valor recebido pelos estados, $25 \%$ são repassados aos seus municípios.

A Contribuição de Intervenção no Domínio Econômico (CIDE) incide sobre a comercialização e importação de petróleo e seus derivados, gás natural e seus derivados e álcool etílico combustível. São repassados obrigatoriamente aos estados $29 \%$ da arrecadação total dessa contribuição para ser aplicado, a priori, em investimentos em infraestrutura de transportes relacionada à comercialização.

O Fundo de Manutenção e Desenvolvimento da Educação Básica e de Valorização dos Profissionais da Educação (Fundeb) tem seu valor definido pelo número de alunos matriculados. Ele é composto por 20\% dos seguintes recursos: FPE, Fundo de Participação dos Municípios (FPM), ICMS, IPIEXP, Imposto Sobre Transmissão Causa Mortis e Doações (ITCMD), IPVA e desoneração de exportações, além da quota parte de 50\% do Imposto Territorial Rural Devida aos Municípios (ITR). Sendo 10\% do total destes recursos destinados ao FUNDEB como complementação quando o valor por aluno não alcançar o mínimo estabelecido.

Para fins desse trabalho, as transferências são classificadas em vinculadas e desvinculadas. De acordo com Nascimento (2010), as primeiras têm destino certo no setor público, como a área da saúde, a da educação etc. Exemplos destas transferências são o Fundo Nacional de Saúde (FNS), o Sistema Único de Saúde (SUS) e o Fundo de Manutenção e Desenvolvimento do Ensino Fundamental e de Valorização do Magistério (FUNDEF) ${ }^{6}$, dentre outras. Por outro lado, as transferências desvinculadas não possuem destino específico a priori, elas servem para equilibrar os orçamentos estaduais e municipais. Exemplos destas transferências são os recursos do Imposto Sobre Produtos Industrializados como compensação aos estados exportadores (IPI-EXP), o FPE e o FPM.

4 Este tópico foi baseado na publicação “Transferências Governamentais Constitucionais” do TCU (2008).

$5 \mathrm{CF} / 88$, Art. 159.

6 A partir de 2007 o FUNDEF tornou-se Fundo de Manutenção e Desenvolvimento da Educação Básica e de Valorização dos Profissionais da Educação (FUNDEB). 


\section{Metodologia}

Para o alcance dos objetivos do trabalho utilizou-se de método econométrico para dados em painel, aplicado sobre informações básicas relacionadas aos aspectos fiscais, econômicas e demográficas dos estados brasileiros e cujas descrições estão dispostas nos subitens que se seguem desta seção.

\subsection{Dados em painel}

Para análise dos efeitos das transferências sobre as despesas públicas dos estados, utilizou-se o método econométrico de dados em painel. Este método é uma junção do modelo de séries temporais e do modelo seção cruzada. O modelo de dados em painel também é denominado de dados combinados ou de dados longitudinais. Existem outras denominações, porém estas são as mais comuns na literatura.

O modelo tem a seguinte especificação:

$$
y_{i t}=\beta_{0}+\beta_{1} x_{1 i t}+\beta_{2} x_{2 i t}+\beta_{3} x_{3 i t}+\cdots+\beta_{k} x_{k i t}+u_{i t}
$$

na qual os erros assumem a seguinte forma:

$$
u_{i t}=\alpha_{i}+v_{i t}
$$

sendo que $\beta_{0}$ é o intercepto; $\beta_{j}$ são os coeficientes angulares correspondentes a cada variável $x_{k i t}=(j=1, \cdots, k) ; k=$ número de variáveis; $i=$ número de unidades de corte transversal; $t=$ número de períodos de tempo; $\alpha_{i}$ é um efeito individual constante no tempo e $v_{i t}$ corresponde a um ruído para cada $i$ no período $t$.

Há dois modelos principais quando se trata de dados em painel: o modelo de efeitos fixos e o modelo de efeitos aleatórios. A diferença básica entre os dois modelos é que no de efeitos fixos o $\alpha_{i}$ está correlacionado com os $x_{i t}$ e no de efeitos aleatórios não há esta correlação.

O modelo de efeitos fixos faz com que o termo de erro $\alpha_{i}$, que está correlacionado com as variáveis $x_{i t}$, seja eliminado através da transformação de efeitos fixos. Os estimadores são estimados por mínimos quadrados ordinários (MQO) agrupados baseados em variáveis temporais reduzidas, ou seja, $\ddot{y}_{i t}=y_{i t}-\bar{y}_{i}$ sendo o mesmo para $\ddot{x}_{i t}$ e $\ddot{u}_{i t}$. Desta forma, com a transformação de efeitos fixos, o modelo a ser estimado assume a seguinte forma:

$$
\ddot{y}_{i t}=\beta_{1} \ddot{x}_{1 i t}+\beta_{2} \ddot{x}_{2 i t}+\beta_{3} \ddot{x}_{3 i t}+\ldots+\beta_{k} \ddot{x}_{k i t}+u_{i t}
$$

Essa transformação de efeitos fixos também é denominada de transformação interna devido à estimação por MQO utilizar a variação de tempo em $y \mathrm{e}$ $x$ dentro (within) de cada unidade de corte transversal. A variação entre 
(between) as unidades de corte transversal é usada na estimação, que também pode ser por MQO, de uma equação na qual o intercepto está presente. Neste caso, o uso do modelo de efeitos aleatórios é o mais adequado (Wooldridge, 2006).

O modelo de efeitos aleatórios, por considerar que o termo de erro $\alpha_{i}$ não está correlacionado com as variáveis $x_{i t}$, permite que os coeficientes possam ser estimados como um único corte transversal, não necessitando da estrutura de dados em painel. Contudo, este modo de estimação desconsidera informações importantes para a análise relacionadas ao tempo (Wooldridge 2006). O modelo tem a seguinte especificação:

$$
y_{i t}=\beta_{0}+\beta_{1} x_{1 i t}+\beta_{2} x_{2 i t}+\beta_{3} x_{3 i t}+\cdots+\beta_{k} x_{k i t}+u_{i t}
$$

Lembrando que o termo de erro é composto e assume a seguinte forma:

$$
u_{i t}=\alpha_{i}+v_{i t}
$$

Sendo que $\alpha_{i}$ não está correlacionado com as variáveis $x_{i t}$ e $v_{i t}$ podem estar serialmente correlacionados ao longo do tempo.

Para eliminar essa correlação serial, o método mais adequado é o de mínimos quadrados generalizados (MQG).

Contudo, o modelo de efeitos fixos e o de efeitos aleatórios não podem ser aplicados juntos numa mesma regressão. Logo, há que se decidir sobre qual dos modelos é o mais adequado. Para isso, existe o teste de Hausman que se baseia na diferença entre os estimadores de efeitos aleatórios e os de efeitos fixos.

De acordo com Wooldridge (2001), a forma original da estatística de Hausman pode ser computada pela seguinte forma quadrática:

$$
H=\left(\hat{\delta}_{F E}-\hat{\delta}_{R E}\right)^{\prime}\left\lceil\operatorname{Ava} r\left(\hat{\delta}_{F E}\right)-\left.\operatorname{Av} \hat{a} r\left(\hat{\delta}_{R E}\right)\right|^{-1}\left(\hat{\delta}_{F E}-\hat{\delta}_{R E}\right)\right.
$$

na qual $\hat{\delta}_{F E}$ representa o vetor das estimativas de efeitos fixos; $\hat{\delta}_{R E}$ representa $o$ vetor as estimativas correspondentes aos efeitos aleatórios; Avâr $\left(\hat{\delta}_{F E}\right)$ representa a estatística do efeito fixo; e $A v \hat{a} r\left(\hat{\delta}_{R E}\right)$ representa a estatística do efeito aleatório.

A hipótese de nulidade do teste de Hausman é que há exogeneidade entre o termo de efeito individual $\alpha_{i}$ e as variáveis do modelo $x_{i t}$, ou seja, o modelo é de efeitos aleatórios. A rejeição desta hipótese implica na adoção do modelo de efeitos fixos (Baltagi, 2005). 
Além do teste de Hausman, outros são necessários para a análise de regressão, como os testes de autocorrelação e heterocedasticidade. Estes testes são essenciais para o cumprimento das premissas básicas do modelo de regressão ${ }^{7}$. No caso de dados em painel, o teste para correlação serial também se faz necessário.

O teste usado para detectar a correlação serial foi o teste de Wooldridge para autocorrelação em dados em painel. E o teste para a detecção da heterocedasticidade foi o de Breusch-Pagan.

\subsection{Modelo econométrico de determinação das despesas estaduais}

O modelo que será utilizado na análise leva em consideração as principais transferências vinculadas e desvinculadas, além do PIB de cada estado. A equação que representa o modelo a ser desenvolvido é a seguinte ${ }^{8}$ :

$$
\begin{aligned}
& \text { desp }_{i t}=\alpha_{0}+\alpha_{1} \text { transv }_{i t}+\alpha_{2} \text { transd }_{i t}+\alpha_{3} \text { pib }_{i t}+ \\
& \alpha_{4} \text { rectrib }_{i t}+a_{5} \text { pop }_{i t}+\alpha_{6} \text { popq }_{i t}+\alpha_{7} \text { dresult }+u_{i t} \text { (07) }
\end{aligned}
$$

Em que:

desp $p_{i t}=$ despesa do estado $i$ no ano $t$;

$\operatorname{trans}_{i t}=$ transferências vinculadas do estado $i$ no ano $t$;

transd $_{i t}=$ transferências desvinculadas do estado $i$ no ano $t$;

$p i b_{i t}=$ PIB do estado $i$ no ano $t$;

rectrib $_{i t}=$ receita tributária do estado $i$ no ano $t$;

$p o p_{i t}=$ população do estado $i$ no ano $t$;

$p o p q_{i t}=$ população elevada ao quadrado do estado $i$ no ano $t$;

dresult $_{i t}=$ dummy do resultado nominal do estado $i$ no ano $t$, sendo 1 para superávit e o para déficit;

$u_{i t}=$ termo de erro composto.

Espera-se que os coeficientes estimados sejam todos estatisticamente significativos.

8 Aplicaram-se logaritmos naturais sobre todas as variáveis, com exceção de, que é uma dummy. 
As variáveis pop (e seu quadrado) e dresult estão diretamente relacionadas ao orçamento público e, portanto, aos gastos. Por isso foram adicionadas como variáveis de controle. Espera-se que $\alpha_{5}<0$, indicando haver ganho de escala na prestação de serviços públicos. Por outro lado, se $\alpha_{6}>0$, então há a indicação de que, a partir de certo ponto, haverá deseconomia de escala, pois o crescimento populacional implicaria maior complexidade das demandas sociais e dificuldade de os estados em atendê-las de forma mais eficiente, eficaz e efetivo. Com relação ao resultado fiscal, se $\alpha_{7}>0$, pode-se dizer que se houver superávit fiscal, haverá incentivo positivo para aumento de gastos, já que houve uma sobra de verbas fiscais e indicação de controle sobre as contas públicas.

As receitas tributárias também se relacionam ao orçamento público e de forma bastante direta; elas são fixadas (estimadas) por lei no orçamento fiscal. Geralmente prevê-se aumento dessas receitas, motivo pelo qual se espera que o coeficiente de rectrib seja positivo $\left(\alpha_{4}>0\right)$, ou seja, que essas receitas aumentem os gastos, confirmando as fixações orçamentárias. Este fato comprovaria a institucionalização das receitas no orçamento, resguardando o elo entre receitas e despesas e confirmando o Modelo de Peacock e Wiseman e a Teoria da Ilusão Fiscal.

Espera-se que os coeficientes das transferências vinculadas e desvinculadas sejam positivos $\left(\alpha_{1}, \alpha_{2}>0\right)$, pois as despesas tendem a aumentar quanto mais transferências os estados receberem, como discutido pela teoria e confirmado na pesquisa de Nascimento (2010).

Também, de acordo com a exposição teórica, especificamente, a Lei de Wagner, espera-se que a renda (pib) apresente coeficiente positivo $\left(\alpha_{3}>0\right)$.

A esta altura, vale destacar os seguintes fatos: se $\alpha_{1}, \alpha_{2}>\alpha_{4}$, está-se diante do indício de ilusão fiscal. Caso em que esta ilusão pode ser suficiente para quebrar o elo entre receitas e despesas. Além disso, se $\alpha_{2}>\alpha_{3}$, além de reforçar o indício de ilusão fiscal, está-se diante do efeito flypaper, ou seja, as transferências desvinculadas apresentam um efeito expansivo sobre os gastos públicos estaduais.

\subsection{Dados, fontes e períodos}

As transferências vinculadas e desvinculadas, as receitas tributárias, as despesas e o resultado nominal de cada estado foram obtidas no site oficial do Tesouro Nacional através do sistema Finanças do Brasil (FINBRA) ${ }^{9}$. O PIB e a população foram obtidos do IBGE. 
A periodicidade das variáveis é anual, correspondendo ao período de 2000 a 2008. O ano de 2000 foi o limite inferior do período porque nem todas as variáveis se encontravam disponíveis para os anos anteriores. Por outro lado, o ano de 2008 foi o ano mais recente que se tem à disposição para todas as variáveis. Cabe lembrar que as variáveis foram logaritmizadas, com exceção da variável que representa o resultado nominal, pois esta é uma dummy.

No modelo utilizado, usou-se as transferências ditas vinculadas e as desvinculadas. As transferências vinculadas foram representadas pelos seguintes recursos: CIDE e FUNDEF/FUNDEB. Por outro lado, fazem parte das transferências desvinculadas: o FPE a cota parte do Imposto Sobre Operações Financeiras (CIOF), IPI-EXP e Auxílio Financeiro Para Fomento às Exportações (FEX). Ressalta-se que o modelo foi estimado pelo software Stata, versão 11.

\title{
4. Resultados e Discussões
}

\subsection{Aspectos gerais sobre a economia e as finanças públicas das regiões e estados brasileiros}

Esta seção pretende prestar discrições gerais sobre as principais variáveis econômicas dos estados, dando ênfase as que constam em seus orçamentos fiscais. O objetivo aqui é mostrar a importância dessas variáveis no período de 2000 a 2008 em termos regionais, especificando, em algumas situações, a importâncias de estados selecionados.

\subsection{PIB, despesas públicas, receitas tributárias e transferências fiscais}

\begin{abstract}
A Região Sudeste é sabidamente a região mais rica do Brasil. Segundo a Figura 1, nessa região está o estado que possui maior PIB, São Paulo. Ele representou $63,8 \%$ do PIB regional em 2000 e 61,6\% em 2008. Os estados da Região Norte são os que apresentam um menor PIB dentro do período analisado, destacando-se o Pará com o maior PIB que, em 2000, representou 36,8\% e em 2008, 37,8\%. O estado com o menor PIB foi o Acre, representando 4,2\% do PIB da região em 2000 e 4,4\% em 2008.
\end{abstract}




\section{FIGURA 1. PIB DAS REGIÕES BRASILEIRAS}

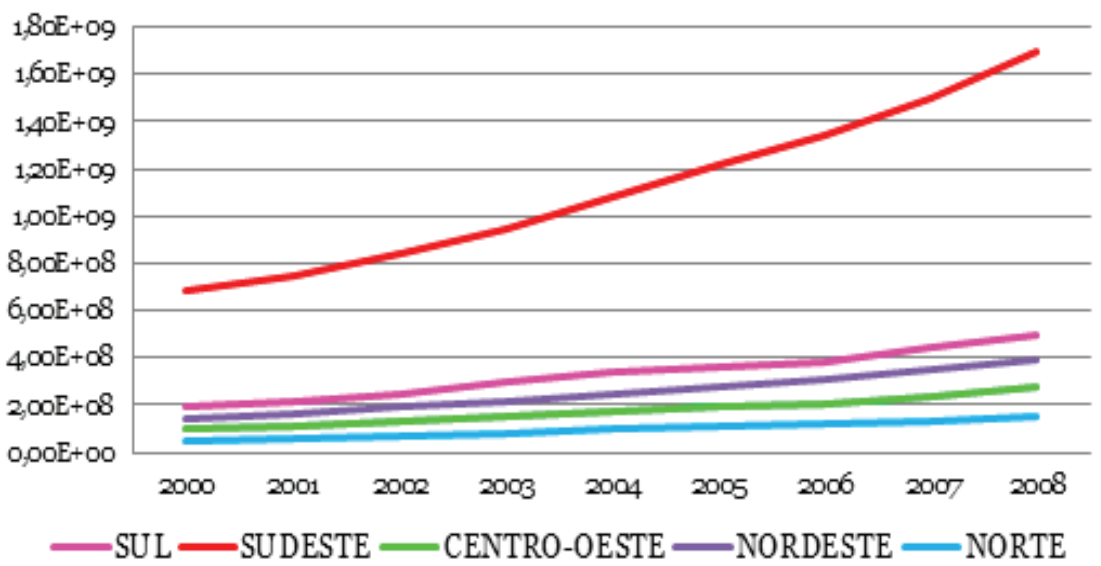

FONTE: elaborado a partir dos dados do Tesouro Nacional.

Observa-se que há uma discrepância entre o PIB da Região Sudeste, que cresce potencialmente, e o PIB das demais regiões, que cresce a uma taxa polinomial. Além disso, o PIB da Região Sudeste tende a continuar aumentando, potencializando a discrepância.

Quanto às despesas, a Figura 2 mostra que a Região Sudeste apresenta os maiores gastos estaduais, comparativamente às demais regiões brasileiras.

FIGURA 2. DESPESAS ESTADUAIS AGREGADAS POR REGIÃO BRASILEIRA

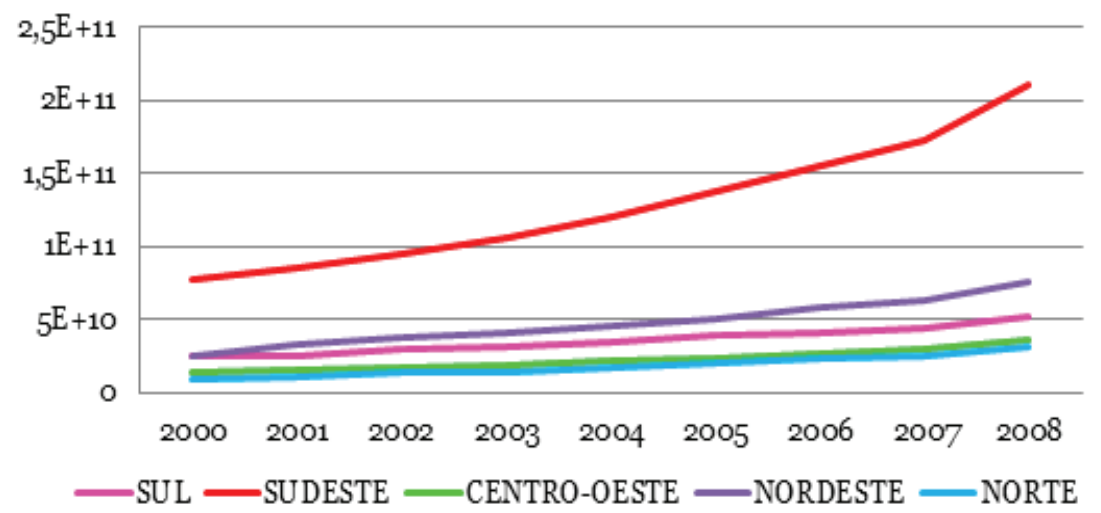

FONTE: elaborado a partir dos dados do Tesouro Nacional.

Dentro desta região destaca-se o estado de São Paulo, representante de 58,2\% dos dispêndios em 2000 e de 60,1\% em 2008. A Região Norte apresenta as menores despesas regionais dentro do período analisado, destacando-se os 
estados do Pará com as maiores despesas (30,2\% em 2000 e 29,6\% em 2008) e de Roraima com as menores despesas (6,6\% em 2000 e 5,6\% em 2008).

Observa-se que há uma discrepância entre as despesas da Região Sudeste, que cresce com tendência exponencial, e as despesas das demais regiões, que crescem com tendências mais lineares. Como resultado, a Região Sudeste tende a se distanciar das demais regiões em termos de despesas públicas. Pode-se cogitar que esta região necessitará financiar-se de forma mais importante que as demais regiões a partir de recursos próprios ou de terceiros.

As transferências intergovernamentais são importantes fontes de financiamento de despesas públicas. Estes recursos são transferidos entre governos, sendo, geralmente, a União um transferidor líquido. Os estados percebem transferências da União, ao mesmo tempo em que também transfere a outros estados e a municípios.

As transferências visam garantir a autonomia política e administrativa de estados e municípios por meio da descentralização da atividade estatal, bem como o equilíbrio dos orçamentos pela desconcentração espacial das fontes de receita fiscal. As transferências da União provêm de tributos federais, cuja arrecadação é maior nos estados mais desenvolvidos, como os das regiões Sul e Sudeste. A distribuição desses recursos não é proporcional e as regiões Norte, Nordeste e Centro-Oeste são mais beneficiadas por apresentarem menores níveis de desenvolvimento (Cossio, 2002; Maciel et al., 2006). As principais transferências aos Estados são o FPE que derivam de tributos principalmente das Regiões Sul e Sudeste. A Região Norte, embora receba proporcionalmente mais recursos de transferências aos estados que a Região Sudeste, apresenta menor concentração da receita tributária (Figura 3).

Figura 3. DIVISÃO DA RECEITA TRIBUTÁRIA POR REGIÃO BRASILEIRA

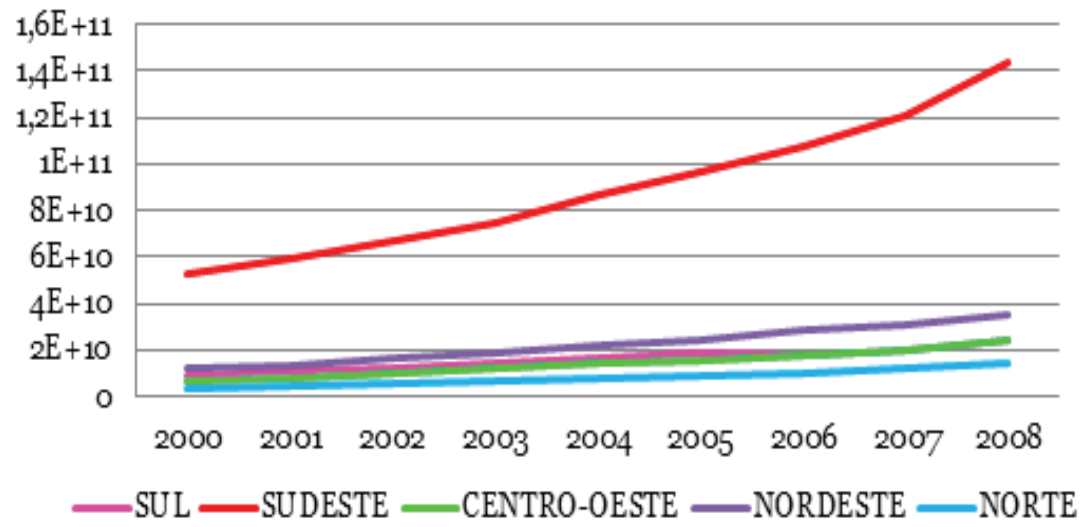

FONTE: elaborado a partir dos dados do Tesouro Nacional. 
Observa-se que há uma grande discrepância entre a receita tributária da Região Sudeste em relação às demais regiões. Além disso, a receita desta região tende a aumentar cada vez mais a diferença devido a seu crescimento mais acelerado que nas demais regiões.

Para Maciel et al. (2006), as transferências utilizadas para a promoção de crescimento equitativo entre as regiões são o FPE, o FPM ${ }^{10}$, o FUNDEF (atual FUNDEB), o FEX, a CIDE, e os Fundos Constitucionais Regionais - Fundo Constitucional do Nordeste (FNE), Fundo Constitucional do Norte (FNO) e Fundo Constitucional do Centro Oeste (FCO).

No período de 2000 a 2008, os estados que mais receberam transferências vinculadas localizam-se na Região Sudeste, como mostra a Figura 4. Dentro desta região, destaca-se o estado de São Paulo, que em 2000 recebeu, aproximadamente, $72,2 \%$ das transferências vinculadas percebidas por essa região. Este percentual reduziu em 2008 para cerca de 65,2\%. Esta queda na participação de São Paulo foi compensada pelo aumento da participação dos demais estados.

Percebe-se, então, que o caráter redistributivo e de redutor das desigualdades sociais não é feito com descapitalização importante da Região Sudeste.

\section{Figura 4. TRANSFERÊNCIAS VINCULADAS RECEBIDAS PELAS REGIÕES BRASILEIRAS}

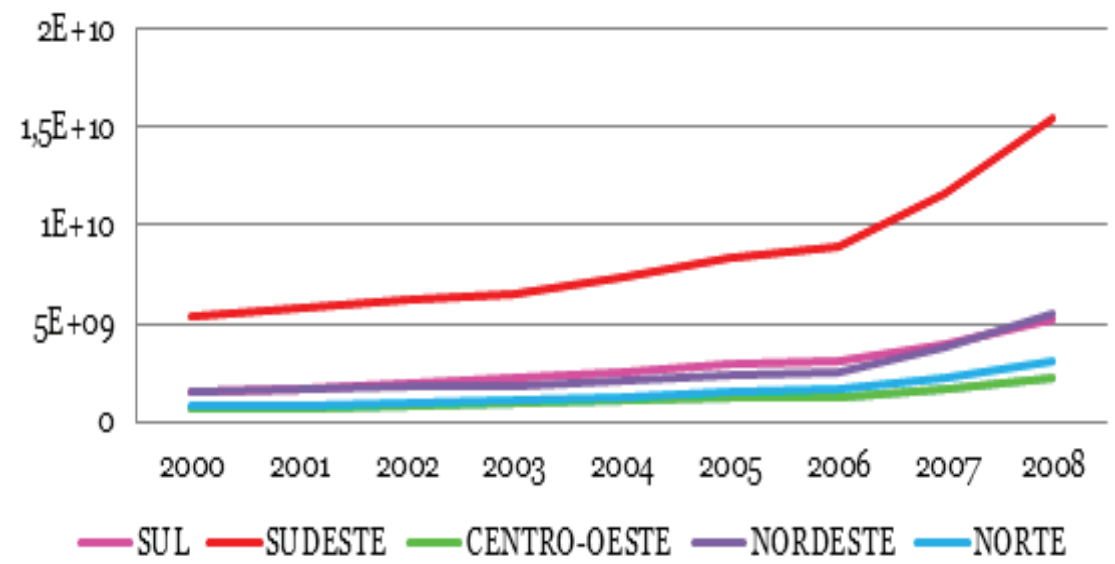

FONTE: elaborado a partir dos dados do Tesouro Nacional. 
Os estados da Região Centro-Oeste foram os que menos receberam transferências vinculadas no período analisado. Goiás destaca-se por receber a maior parte destas transferências destinadas a esta região $(48,6 \%$ em 2000 e $43 \%$ em 2008). O Distrito Federal também merece destaque por receber menos deste tipo de transferência, representando em 2000, 3,7\% das transferências vinculadas recebidas pela Região Centro-Oeste, ampliando sua participação em 2008 para 4,4\%.

Quanto às transferências desvinculadas, a Região Nordeste é a que mais se beneficiou, como mostrado na Figura 5. Destacam-se o estado da Bahia com maior participação no período (19,5\% em 2000 e 19\% em 2008) e Sergipe com menor participação (7,6\% em 2000 e 7,7\% em 2008. A região que menos recebeu este tipo de transferência foi a Centro-Oeste, tendo Goiás como destaque por receber a maior parte $(37,6 \%$ em 2000 e $37,9 \%$ em 2008) e o Distrito Federal por receber menos das transferências desvinculadas (10\% em 2000 e $8,7 \%$ em 2008).

\section{Figura 5. TRANSFERÊNCIAS DESVINCULADAS RECEBIDAS PELAS REGIÕES BRASILEIRAS}

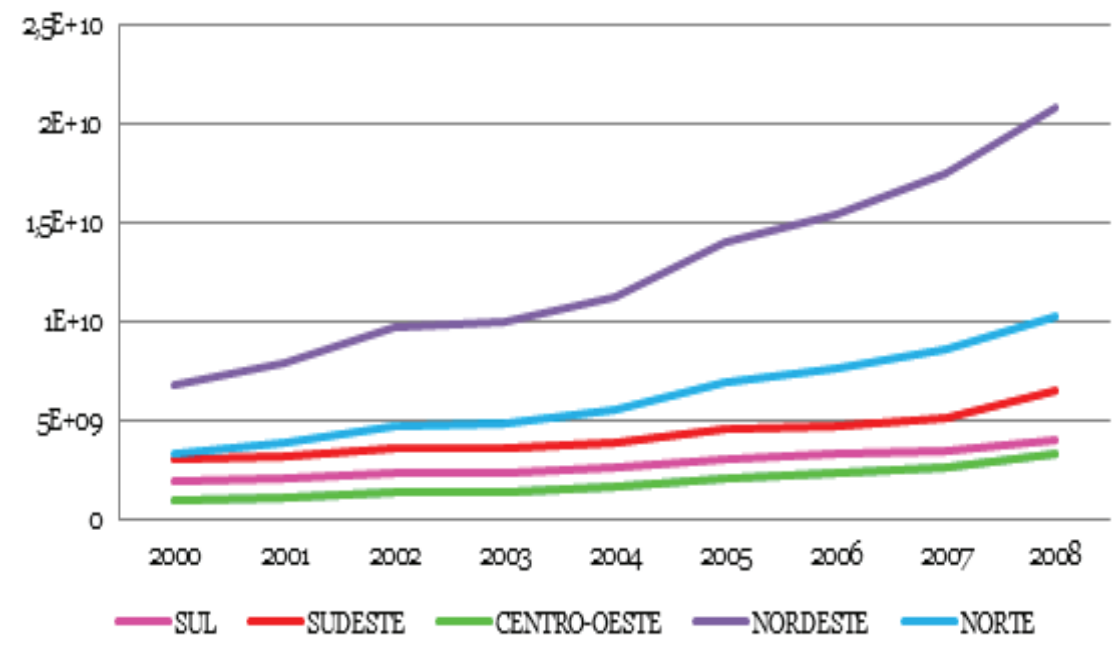

FONTE: elaborado a partir dos dados do Tesouro Nacional.

Assim como nas transferências vinculadas, também é observado um crescimento acelerado nas transferências desvinculadas, porém, desta vez na Região Nordeste comparativamente às demais regiões. Este resultado faz aumentar cada vez mais o volume destes recursos para o Nordeste frente às outras regiões. 


\subsection{Testes para escolha do modelo}

A escolha do modelo implicou em aplicar os testes para determinar se o modelo a ser estimado seria o de efeitos fixos ou de efeitos aleatórios. Foi necessário também encontrar o melhor método para estimação dos coeficientes. Desta forma, foram aplicados testes para detecção ou não de heterocedasticidade e autocorrelação. Todos estes resultados são apresentados a seguir.

O teste de Hausman $\left(x^{2}=9,550 ;\right.$ prob $\left.=0,215\right)$ mostrou que o melhor modelo a ser estimado é o de efeitos aleatórios e o teste multiplicador de Lagrange ( $\mathrm{x}^{2}$ $=223,33 ;$ prob $=0,000$ ) reafirma que este é o melhor modelo a ser ajustado.

O teste de correlação serial $(\mathrm{F}=8,764 ;$ prob $=0,006)$ confirmou a presença da mesma, sendo detectada a correlação de primeira ordem. O teste de heterocedasticidade $\left(\mathrm{x}^{2}=1,410\right.$; prob $\left.=0,235\right)$ confirmou a ausência da mesma, ou seja, os erros são homoscedásticos.

Sendo assim, o modelo foi estimado por MQG para a correção da correlação serial.

\subsection{Resultados do modelo estimado}

As principais informações relacionadas a esta equação estão sintetizadas na Tabela 1. Nesta tabela, as variáveis que mais influenciam o aumento das despesas são a população, o PIB e as receitas tributárias, além das demais não incluídas no modelo, como pode ser observado pelo valor da constante.

Tabela 1. RESULTADOS DO MODELO

\begin{tabular}{l|c|c|c|c}
\hline Variável & Coeficiente & Erro-padrão & Estatística $Z$ & $\mathrm{P}>|Z|$ \\
\hline constante & 19,614 & 2,002 & 9,80 & 0,000 \\
transv & $-0,048$ & 0,026 & $-1,86$ & 0,063 \\
transd & 0,211 & 0,023 & 9,07 & 0,000 \\
pib & 0,460 & 0,054 & 8,52 & 0,000 \\
rectrib & 0,329 & 0,054 & 6,09 & 0,000 \\
pop & -2.044 & 0,268 & $-7,62$ & 0,000 \\
popq & 0,066 & 0,009 & 7,41 & 0,000 \\
dresult & 0,036 & 0,011 & 3,26 & 0,001 \\
\hline $\mathrm{R}^{2}=0,987$ & \multicolumn{3}{|c}{$\mathrm{No}^{0}$ de obs. $=244$} \\
\hline
\end{tabular}

FONTE: elaborado pelos autores. 
O modelo foi bem ajustado uma vez que $\mathrm{o} \mathrm{R}^{2}$ foi alto, indicando que as variáveis independentes contidas nele explicam $98,69 \%$ da variação nas despesas estaduais, sendo o restante explicado por variáveis que, aparentemente, não foram incluídas no modelo, mas estão presentes no termo de erro.

A variável transv, embora não tenha sido significativa a $5 \%$, o foi a $6,3 \%$. Sendo assim, quando essas transferências aumentam em 1\%, as despesas públicas estaduais diminuem em o,048\%. Apesar de muito baixo, este valor não foi o esperado, mas poderia ser justificado pelo fato de que a vinculação de recursos diminui a discricionariedade do gestor público, contornando assim parte do fenômeno da ilusão fiscal.

Por outro lado, as transferências desvinculadas aumentam em 0,211\% as despesas a cada vez que aquelas aumentam em $1 \%$. Quer dizer que, quando o gestor público recebe transferências que $a$ priori não tem destino certo há um aumento nas despesas estaduais.

O aumento ainda é maior $(0,460 \%)$ quando a renda aumenta em $1 \%$. O fato de o coeficiente de transd $(0,211)$ ser menor que o de pib $(0,460)$ evidencia a ausência do efeito expansivo das transferências desvinculadas, ou seja, não há indicativo do efeito flypaper sobre as despesas públicas estaduais. Por outro lado, o fato de o coeficiente da renda ser menor que a unidade também descarta a Lei de Wagner, apesar de mostrar expansão sobre as despesas totais. Dentre as variáveis consideradas, a renda ainda é a maior responsável pelo crescimento das despesas, por apresentar coeficiente menos inelástico.

Quanto às receitas tributárias, estas aumentam as despesas em 0,329\% a cada 1\% de aumento na arrecadação. É notável que as receitas tributárias tenham maior efeito, quanto ao aumento das despesas públicas estaduais, do que as transferências recebidas pelos estados. $\mathrm{O}$ fato de o coeficiente das despesas desvinculadas apresentarem coeficiente menor do que da arrecadação, mostra que a ilusão fiscal não é capaz de quebrar o elo entre receitas e despesas públicas ou ela não se faz tão presente.

As despesas públicas diminuem em 2,044\% quando a população aumenta em $1 \%$, indicando ganho de escala na produção de serviços públicos. Contudo, quando consideramos o quadrado da população, as despesas aumentam em 0,066\% a cada $1 \%$ de aumento, indicando, como esperado, que a medida que a população cresce a partir de certo ponto é necessário o aumento dos gastos governamentais para dar conta de demandas maiores e mais complexas.

Finalmente, quando, no ano anterior ao analisado, o resultado nominal tiver mostrado superávit, a despesa aumenta em 0,036\% no ano seguinte. Ou seja, quando há déficit, o gestor público é mais cauteloso ao administrar as despesas. Esse fato evidencia que o resultado fiscal do ano imediatamente anterior afeta o comportamento fiscal dos estados. 
De uma forma geral, os resultados parecem mostrar que os gastos dos estados brasileiros não sofrem de vários dos fenômenos encontrados em outros trabalhos empíricos (flypaper effect, Lei de Wagner etc.). Ao invés disso, parece haver certo controle sobre as finanças estaduais. Esse fato talvez seja verdadeiro para o conjunto dos estados, entretanto, não se garante que o seja para estados isolados.

\section{Conclusões}

As transferências vinculadas e desvinculadas possuem uma evolução semelhante nas regiões, porém existe uma disparidade muito grande entre a Região Sudeste e as demais, no que diz respeito às transferências vinculadas e entre a Região Nordeste e as demais, no que diz respeito às transferências desvinculadas.

Quando se procurou saber sobre os efeitos dessas transferências nas despesas estaduais, observou-se que as transferências vinculadas não apresentaram efeito expansivo sobre assas despesas, mas, pelo contrário, o modelo utilizado mostrou que estas diminuem quanto mais deste tipo de recursos os estados recebem. As transferências desvinculadas, por sua vez, também não apresentaram efeito expansivo, uma vez que o efeito flypaper não foi verificado. No geral, diante o método aplicado sobre as informações utilizadas e das informações geradas, pode-se afirmar que as transferências fiscais recebidas pelos estados brasileiros não apresentam efeito expansivo sobre os gastos públicos estaduais. Uma das possíveis explicações pode ser a indicação de que ilusão fiscal, fenômeno explicativo do efeito flypaper, não estar presente. Esta indicação pode ser reforçada pelo fato de o coeficiente estimado das receitas tributárias ser maior que o das transferências, não se podendo negar que há um vínculo certo e direto entre as despesas estaduais e as receitas tributárias estaduais. Esses resultados indicam uma rejeição da hipótese colocada, qual seja que as transferências apresentam efeito expansivo sobre os gastos estaduais.

Observou-se também que o aumento da renda foi positivo, como previa a Lei de Wagner, contudo, esta foi refutada devido à elasticidade renda ser menor que a unidade. $\mathrm{O}$ que quer dizer que, neste caso, o crescimento das despesas não foi exponencialmente mais rápido que o da renda. As receitas tributárias e o resultado fiscal também tiveram resultados como esperado, sendo que o efeito das primeiras afasta as evidências de ilusão fiscal.

Com relação à população, o modelo mostrou que ela foi um fator importante para a determinação das despesas públicas estaduais. Seu tamanho pode indicar ganho de escala na prestação dos serviços públicos. Outro fato é que, a partir de certo tamanho, ela pressiona o setor privado para o 
cumprimento de suas exigências. Ou seja, quando ela cresce, o setor público passa a ser pressionado para o atendimento de demandas condizentes com a complexidade da vida contemporânea.

Por fim, pode-se observar que o resultado fiscal, quando superavitário, apresenta efeito direto sobre os gastos. Assim, poder-se-ia cogitar que um superávit pode provocar um aumento de gastos devido a percepção de disponibilidade de recursos para financiá-los e pela sensação de controle sobre as contas públicas.

Cabe alertar que esses resultados são representativos para o conjunto dos estados, ou seja, um estudo tomando estados específicos poderia chegar a conclusões divergentes ou convergentes às apresentadas aqui.

Dados complementares do artigo disponível em:

$<$ http://ojs.c3sl.ufpr.br/ojs2/index.php/economia/article/view/24813/19499> 


\section{Referências Bibliográficas}

BALTAGI, B. H. (2005). Econometric analysis of panel data. England: J. W. Sons.

BRASIL. Constituição (1988). Constituição da República Federativa do Brasil: promulgada em 5 de outubro de 1988. Brasília, DF: Senado Federal.

COSSIO, F. A. B. (2002). Ensaios sobre federalismo fiscal no Brasil. Programa de Pós-Graduação em Economia. Tese (Doutorado). Rio de Janeiro: PUC/RJ.

FISHER, R. (1991). "Income and grant effects on local expenditures: the flypaper effect and other difficulties". Journal of Urban Economics, 12; p. 324-345.

IBGE (2011). URL [on-line]: <http://www.ibge.gov.br/estadosat/>. Acesso em: 17 de jan. de 2011.

INGBERMAN, D. E.; INMAN, R. P. (1987). “The political economy of fiscal policy”. National Bureau of Economics Research, WP, 240; p. 1-67. URL [on-line]: <http://www.nber.org/papers/w2405>. Acesso em: 10 de jan. de 2011.

MACIEL, P. J.; ANDRADE, J.; TELES, V. K. (2006). "Transferências fiscais e convergência regional”. URL [on-line]: <http://www.bnb.gov.br/content/aplicacao/ Eventos/forumbnb2006/docs/transferencias.ppd>. Acesso em: 20 de jan. 2011.

MOURÃO, P. J. R. (2004). Determinantes da despesa pública em Portugal: uma avaliação econométrica. Escola de Economia e Gestão. Dissertação (Mestrado). Universidade do Minho. URL [on-line]: <http://repositorium.sdum.uminho. pt/bitstream/1822/942/2/tesepmourao.pdf>. Acesso em: 26 de fev. de 2011.

NASCIMENTO, J. S. (2010). Efeitos das transferências financeiras sobre os gastos e a arrecadação dos municípios brasileiros. Programa de Pós-Graduação em Economia Aplicada. Tese (Doutorado). Viçosa: UFV/MG.

OATES, W. (1979). "Lump-sum Intergovernmental grants have price effects". In: MIESZKOWSKI, P.; OAKLAND, W. [ed.]. Fiscal federalism and grantsinaid. Washington, DC.

TESOURO NACIONAL. URL [on-line]: <http://www.tesouro.fazenda.gov.br/ estados_municipios/estados.asp>. Acesso em: 20 de jan. de 2011.

TRIBUNAL DE CONTAS DA UNIÃO - TCU (2008). Transferências governamentais constitucionais. Brasília: TCU.

VARELA, P. S.; MARTINS, G. A.; FAVERO, L. P. L. (2010). "Ineficiência do gasto público e ilusão fiscal: uma avaliação do flypaper effect na atenção básica à saúde". IV Congresso ANPCONT. URL [on-line]: <http://www.anpcont.com. $\mathrm{br} /$ site/docs/congressoIV/o1/CCG330.pdf> . Acesso em: 20 de jan. de 2011.

WILGES, I. J. (2006). Finanças públicas: orçamento e direito financeiro. Porto Alegre: AGE.

WOOLDRIDGE, J. M. (2001). Econometrics analysis of cross section and panel data. MIT Press.

WOOLDRIDGE, J. M. (2006). Introdução à econometria: uma abordagem moderna. São Paulo: Thomson.

Recebido em: 25 de outubro de 2011

Aceito em: 26 de novembro de 2012 